\title{
Deprivation time and the initiation of drinking'
}

GLENN I. HATTON and WILLIAM R. IVES, ${ }^{2}$ Michigan State University, East Lansing, Mich. 48823

Differing dehydration states were produced by varying hours of deprivation from $072 \mathrm{~h}$. The speed with which Ss began drinking and the amount of water consumed varied directly with dehydration levels lower than those associated with the habituation conditions. Higher levels resulted in higher intakes and unchanging latencies to drink.

The water-oriented behaviors of thirsty and satiated animals are far from being well understood. A large body of evidence has been amassed to show that water intake is directly related to level of dehydration, whether the dehydration is produced by hours of deprivation (Siegel, 1947; Stellar \& Hill, 1952) or by "artificial" means (O'Kelly \& Beck, 1960). Lick rates, however, do not vary systematically with deprivation time (Stellar \& Hill, 1952). Latency to drink was reported by Bolles (1965) to be invariant over deprivation times between 7 and $42 \mathrm{~h}$, when deprivation times were randomly administered. The activation of drinking behavior by deprivation periods shorter than $7 \mathrm{~h}$ and longer than $42 \mathrm{~h}$ remains relatively unstudied, except under somewhat special conditions (Bolles, 1962). These first $7 \mathrm{~h}$ are important because it is during this time that the rat goes from a condition of satiety to a dehydration state sufficient to produce water intakes up to $4-5 \%$ of body weight (Bolles, 1965). Deprivation times longer than $42 \mathrm{~h}$ are of interest in testing the inverted-U hypothesis (cf. Bélanger \& Feldman, 1962) as well as extending the generality of the functions obtained with shorter deprivation times.

\section{EXPERIMENT 1 \\ Method}

Twelve male albino rats, about 100 days of age at the start of the experiment, served as $\mathrm{Ss}$, and were housed in individual cages in a temperature controlled room under constant light conditions. Wayne lab blox were constantly available in their living cages. Two six-unit drinking boxes with individual Plexiglas covers were used for observations of drinking. Each unit was fixed with a $100-\mathrm{ml}$ gas measuring tube, graduated in $0.2 \mathrm{ml}$. Latencies were measured with $.01-\mathrm{sec}$ timers (and stopwatches for latencies longer than $1 \mathrm{~min}$ ). The Ss were given 17 days of habituation to a 23.5-h water deprivation schedule prior to the start of the experimental treatments. By the end of this time, latencies were stable within E's reaction time. During this 17 -day period, Ss were allowed 0.5 -h free access to water in the drinking boxes at the same time each day. Predrink body weight, latency to drink, and amount drunk were recorded daily. Latency to drink was the elapsed time between opening of a Plexiglas guillotine door in front of the water spout and $S$ licking at the spout. After adaptation, Ss were divided randomly into two groups of six Ss each, and treatments were begun. On consecutive treatment days, which were separated by 3 days of ad lib conditions, one group was deprived of water for $0,0.5,1,2$, $4,8,23.5,23.5,4,2,1,0.5,0$ h. This group was designated the ascending-thendescending group (A-D). The other group (D-A), started with 23.5 -h deprivation, progressed through a similar, but inverted, series and ended with the $23.5 \mathrm{~h}$ condition. Water bottles were removed from the home cages at predetermined times, so that, on treatment days, access to water came at S's usual daily drinking time.

\section{Results}

In the top part of Fig. 1, the means of reciprocal latency to drink are plotted as a function of hours of water deprivation, on a $\log$ scale. Analysis of variance showed these means to differ significantly $(F=24.78$, $\mathrm{df}=6 / 60, \mathrm{p}<.001)$. The interaction of Groups by Orders was significant $(F=5.96$, $\mathrm{df}=1 / 10, \mathrm{p}<.05)$. This was due to both groups drinking with shorter latencies the second times they experienced the treatments than they did the first time. No other reliable effects were obtained.

The lower part of Fig. 1 presents the means for water intake expressed as a percentage of body weight (BW), and plotted as a function of hours of deprivation on a log scale. The main effect for hours of deprivation was significant $(F=53.87$, $\mathrm{df}=6 / 60, \mathrm{p}<.001)$. The mean per cent BW in take of the D-A group was reliably higher than that of the A-D group $(F=8.91$, $\mathrm{df}=1 / 10, \mathrm{p}<.025)$. A significant interaction $(F=6.58, \mathrm{df}=1 / 10, \mathrm{p}<.05)$ of Groups by Orders was produced by larger intakes associated with the order experienced last, i.e., the D-A group drank more under the ascending conditions and the A-D group drank more under the descending conditions. This finding was consistent with the latency data mentioned above. In neither the latency data nor the intake data were there any interactions with hours of deprivation. Therefore, the relationships of these variables remain as depicted in Fig. 1.

\section{EXPERIMENT 2}

It was clear from the results of Experiment 1 that increasing deprivation time from 0.5 up to $23.5 \mathrm{~h}$ had the effect of enhancing speed of initiation of drinking (reducing latency to drink), even though Ss were thoroughly habituated to the drinking schedule and boxes. It was not clear, however, if this increased speed, as deprivation times approached $23.5 \mathrm{~h}$, was an activation phenomenon or was due to the increasing similarity with the original habituation conditions. Experiment 2 was designed to provide evidence for one or the other of these alternatives by extending deprivation times beyond the 23.5-h habituation conditions. If some kind of drive-stimulus gradient were responsible for the shape of the curves in Experiment 1, then some similarly shaped functions, representing a decrease in speed and/or intake should be evident when dehydration is extreme (cf. Estes, 1958; Fink \& Patton, 1953). Conversely, continued increases in speed and intake at extended deprivation times would indicate that activation of this need-related behavior, at least in the presence of the consummatory object, is not inhibited by drive-stimulus gradients.

\section{Method}

The Ss and apparatus were the same as those used in Experiment 1. After finishing Experiment 1, Ss were placed on ad lib conditions until body weights had stabilized. The Ss were then adapted to 23.5 -h

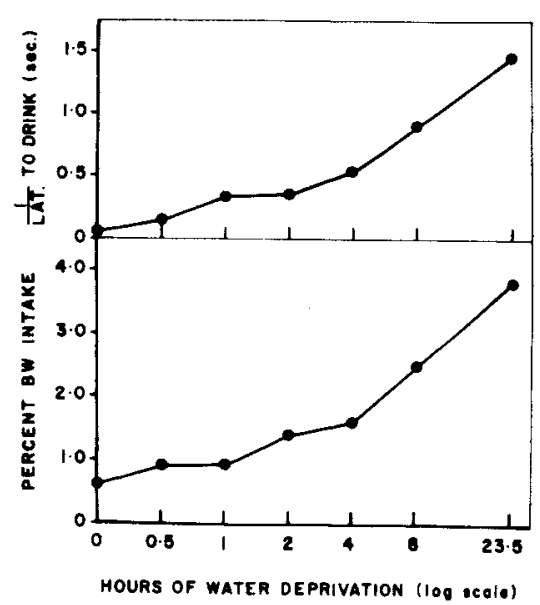

Fig. 1. Mean reciprocal latency to initiate water intake (top) and mean per cent body weight of water consumed (bottom) plotted as a function of hours deprived. 


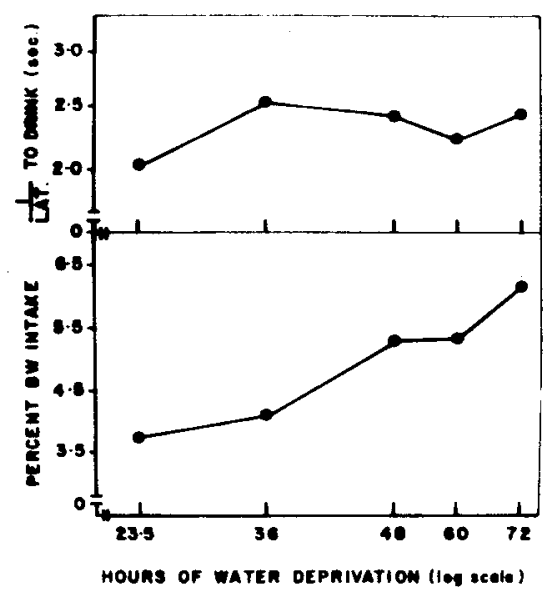

Fig. 2. Mean reciprocal latency to initiate water intake (top) and mean per cent body weight of water consumed (bottom) plotted $a$ a function of hours deprived.

water deprivation as in Experiment 1. At the end of this second adaptation period, Ss were redivided into two groups, such that each group in Experiment 2 was made up of equal numbers of Ss from each group of Experiment 1. One group received an ascending series and the other a descending series of deprivation conditions. The treatments were: $23.5-, 36-, 48-, 60$, and 72-h water deprivation. All other procedures and measurements were the same as in Experiment 1.

\section{Results}

The data of Experiment 2 are plotted in Fig. 2. There were no significant main effects or interactions associated with the reciprocal latency data. Latency to drink did not change with deprivation times beyond $23.5 \mathrm{~h}$. However, as shown in the lower part of Fig. 2, per cent BW intake is a monotonic increasing function of deprivation time, even for these extended periods. These intakes continued to increase despite the fact that Ss had only 0.5 -h free access to water in Experiment 2, just as in Experiment 1. An analysis of variance on these data revealed that only the main effect for hours of deprivation was significant $(F=16.34$, df $=4 / 40, p<.001)$. DISCUSSION

It was not unexpected that Ss of Experiment 1 would drink more and even initiate intake more rapidly as deprivation time increased. These findings are consistent with previous research. It is interesting to note the striking similarity of the curves in Fig. 1. Both functions are relatively flat up to $4 \mathrm{~h}$, then both increase dramatically. Apparently, some time between 2- and 8-h deprivation is necessary to significantly affect water-oriented behavior. The interaction of Groups by Orders on the latency variable was predictable from Bolles' (1965) experiment, in which he found that drinking latencies became shorter with continued testing. It is not clear, however, in the present experiment why a second exposure to a particular deprivation condition should lead to larger intakes. This finding is at variance with that of Stellar \& Hill (1952), who found that rats exposed twice to the same number of hours of deprivation, with a recovery period in between, drank the same amount on both occasions. The possibility that the increased intakes in Experiment 1 were due to deprivation-carry-over effects seems unlikely, since the D-A group drank more on the ascending series even though it had six consecutive treatment days of $1 \mathrm{~h}$ or less deprivation, each being separated by 3 day's on ad lib. Also, it seems that if this recovery period had not been sufficient, it would have produced differential intakes in the ascending and descending conditions of Experiment 2. This, however, was not the case.

The consistent speed with which Ss initiated intake at all times from $23.5 \mathrm{~h}$ to $72 \mathrm{~h}$ of deprivation indicates that there was littlle, if any, drive-stimulus generalization gradient influencing latency to drink. The data in Fig. 2 also leave unsupported the inverted-U hypothesis. There were no applarent inanition influences; the intakes simply increased with water need, and the latencies seemed to reach some limit (perhaps E's reaction time) and remained there. There is some evidence that activation is enhanced in the presence of reinforcement
(O'Kelly, Hatton, Tucker, \& Westall, 1965), and is more easily depressed by such factors as drive-stimuli when reinforcement is withheld (Hatton, 1965).

\section{REFERENCES}

BÉlANGER, D., \& FELDMAN, S. M. Effects of water deprivation upon heart rate and instrumental activity in the rat. Journal of Compantive \& Phy siological Psychology, 1962, 55, 220-225.

BOLLES, R.C. The readiness to eat and drink: The effect of deprivation conditions. Joumal of Comparative \& Phy siological Psychology, 1962, $55,230-234$.

BOLLES, R. C. Consummatory behavior in rats maintained a-periodically. Joum al of Comparative \& Physiological Psychology, 1965, 60, 239-243.

ESTES, W. K. Stimulus-response the ory of drive. In M. R. Jones (Ed.), Nebraska symposium on motivation: 1958. Lincoln: University of Nebraska Press, 1958. Pp. 35-69.

FINK, J. B., \& PATTON, R. M. Decrement of a learned drinking response accompanying changes in several stimulus characteristics. Joumal of Comparative \& Physiological Psychology, 1953, 46, 23-27.

HATTON, G. I. Drive shifts during extinction Effects on extinction and spontaneous recovery of bar-pressing behavior. Joumal of Comparative \& Physiological Psychology, 1965, 59, 385-391.

O'KELLY, L. I., \& BECK, R. C. Water regulation in the rat. III. The artificial control of thirst with stomach loads of water and sodium chloride. Psychological Monographs: General \& Applied, 1960, 74, (13, Whole No. 500).

O'KELLY, L. I., HATTON, G. I., TUCKER, L., \& WESTALL, D. Water regulation in the rat: Heart rate as a function of hydration, anesthesia, and association with reinforcement. Joumal of Comparative \& Phy siological Psy chology, 1965, $59,159-165$

SIEGEL, P. S. The relationship between volun tary water intake, body weight loss, and number of hours of water privation in the rat. Joumal of Comparative \& Phy siological Psy chology, 1947, 40,231-238.

STELLAR, E, \& HILL, J. H. The rat's rate of drinking as a function of water deprivation. Journal of Comparative \& Physiological Psy chology, 1952, 45, 504-507.

\section{NOTES}

1. This research was supported by All-University Research funds from Michigan State University. The authors wish to thank Dr. L. I. O'Kelly and Dr. J. I. John son for their helpful suggestions and critical reading of the manuscript.

2. NSF Undergraduate Fellow, supported by Undergraduate Research Participation Grant GE-6309. 